\title{
APPROXIMATIONS TO RISK THEORY'S $F(x, t)$ BY MEANS OF THE GAMMA DISTRIBUTION
}

\author{
HILARY L. SEAL \\ Ecole Polytechnique Fédérale de Lausanne
}

It seems that there are people who are prepared to accept what the numerical analyst would regard as a shockingly poor approximation to $F(x, t)$, the distribution function of aggregate claims in the interval of time $(0, t)$, provided it can be quickly produced on a desk or pocket computer with the use of standard statistical tables. The so-called NP (Normal Power) approximation has acquired an undeserved reputation for accuracy among the various possibilities and we propose to show why it should be abandoned in favour of a simple gamma function approximation.

Discounting encomiums on the NP method such as Bühlmann's (I974): "Everybody known to me who has worked with it has been surprised by its unexpectedly good accuracy", we believe there are only three sources of original published material on the approximation, namely Kauppi et al (I969), Pesonen (I969) and Berger (I972). Only the last two authors calculated values of $F(x, t)$ by the NP method and compared them with "true" four or five decimal values obtained by inverting the characteristic function of $F(x, t)$ on an electronic computer.

Briefly, the NP method for approximating $F(x, t)$ consists of calculating $y$ from the quadratic $\left(\mathrm{NP}_{2}\right)$ or cubic $\left(\mathrm{NP}_{3}\right)$ equation

$$
\begin{aligned}
\frac{x-t}{\sqrt{\varkappa_{2}}}=y & +\frac{\varkappa_{3} / x_{2}^{3 / 2}}{3 !}\left(y^{2}-\mathrm{I}\right) \\
& +\frac{x_{4} / x_{2}^{2}}{4 !}\left(y^{3}-3 y\right)-\frac{x_{3}^{2} / x_{2}^{3}}{(3 !)^{2}}\left(2 y^{3}-5 y\right)
\end{aligned}
$$

where the kappas are the cumulants of $F(\cdot, t)$, and treating the result as a standardized Normal variate so that

$$
F(x, t) \simeq \Phi(y) \equiv \frac{I}{\sqrt{2 \pi}} \int_{-\infty}^{y} e^{-z^{1 / 2}} d z
$$


Berger (loc. cit.) found that the use, of $x_{4}$ and the inclusion of the last two terms of the foregoing equation in $y$ "does not generally produce better results than NP2". In our view, the necessity of solving a cubic equation and, possibly, choosing the appropriate root (Berger, I972) removes the "second approximation" from the list of simple procedures.

Among the "short cut methods" of approximating $F(x, t)$ tried by Bohman and Esscher in their classic I963-64 paper was the gamma distribution with density

$$
\frac{I}{\Gamma(\alpha)} e^{-y} y^{x-1} \quad 0 \leq y<\infty
$$

so that

$$
F\left(t+z \sqrt{x_{2}}, t\right) \simeq \frac{I}{\Gamma(\alpha)} \int_{0}^{\alpha+z \sqrt{\alpha}} e^{-y} y^{\alpha-1} \equiv P(\alpha, \alpha+z \sqrt{\alpha})
$$

where the $P$-notation for the incomplete gamma ratio is now standard (see, e.g., Magnus et al, Ig66) and $\alpha$ is to be determined from

$$
\alpha=\frac{4}{\varkappa_{3}^{2} / \varkappa_{2}^{3}} \equiv \frac{4}{\gamma_{1}^{2}}
$$

The joint authors reported that "the method has an astonishing accuracy in large parts of the field investigated" and one wonders why it has not been used more widely. The tables of KhamisRudert (I965) allow the approximation to be made with facility. It is mentioned, however, that what we write as $P(a, x)$ is called by Khamis $P(a, 2 x)$; this must be watched when using the tables.

Let us therefore compare the published $\mathrm{NP}_{2}$ and $\mathrm{NP}_{3}$ approximations to $F(x, t)$ with those obtained from (3) and (4). In the appended table the first four $t$-values come from Berger's (I972) Table 2, the next is from Pesonen (I969) and the last two are from Berger's (loc. cit.) Table 3. There are 38 values of $I-F(x, t)$ shown in the Table and the gamma approximation (which is overloaded with decimals in the Table) is better than NP2 in 27 of them. It is better than $\mathrm{NP}_{3}$ in 27 also. What is more important is that the gamma approximation is better than NP2 in 9 of the I2 cases where deviations from the mean are 4,5 or 6 standard deviations; the corresponding number among the dozen similar $\mathrm{NP}_{3}$ cases is 
also 9-but not the same 9! Furthermore, the superiority of the gamma approximation does not seem to depend on the size of $\alpha$, large values of which are supposed to ameliorate the accuracy of the NP method. Surely here is a case for discarding the Normal Power method altogether.

To conclude, it is mentioned that just as the $\mathrm{NP}$ method can be extended to provide stop loss premiums (Pesonen, I969) the same is true of the gamma approximation. The stop loss premium at priority $x$ can be shown to be

$\int_{x}^{\infty}(u-x) d u F(u, t) \simeq \sqrt{\alpha \alpha_{2}} \frac{q^{\alpha} e^{-q}}{\Gamma(\alpha+I)}+(x-t) P(\alpha, q)-(x-t)$ where $q=\alpha+\sqrt{\alpha / \varkappa_{2}}(x-t)$.

No calculations of this quantity were made as it was not thought that any different conclusions would have been drawn. 


\begin{tabular}{|c|c|c|c|c|}
\hline $\begin{array}{l}\text { Individual claim } \\
\text { distribution } \\
\text { (Bohman-Esscher) }\end{array}$ & $\begin{array}{l}\text { Negative } \\
\text { binomial } \\
\text { index }\end{array}$ & - & $z=\frac{x-t}{\sqrt{\varkappa_{2}}}$ & $\alpha$ \\
\hline Non-industrial fire & $\infty$ & IOOO & $\begin{array}{l}0 \\
1 \\
2 \\
3 \\
4 \\
6\end{array}$ & $2.71_{47}$ \\
\hline Non-industrial fire & 20 & 1000 & $\begin{array}{l}0 \\
\text { I } \\
2 \\
3 \\
4 \\
6\end{array}$ & $6.074 \mathrm{I}$ \\
\hline Non-industrial fire & $\infty$ & 100 & $\begin{array}{l}0 \\
1 \\
2 \\
3 \\
4 \\
6\end{array}$ & $0.2714^{8}$ \\
\hline Non-industrial fire & 20 & 100 & $\begin{array}{l}0 \\
\text { I } \\
2 \\
3 \\
4 \\
6\end{array}$ & 0.32569 \\
\hline Life $B$ & $\infty$ & I0OO & $\begin{array}{l}0 \\
1 \\
2 \\
3 \\
4 \\
6\end{array}$ & 2.7056 \\
\hline Non-industrial fire & I & 1000 & $\begin{array}{l}0 \\
1 \\
3 \\
5\end{array}$ & 0.9901 \\
\hline Non-industrial fire & I & 100 & $\begin{array}{l}0 \\
1 \\
3 \\
5\end{array}$ & $0.5^{854}$ \\
\hline
\end{tabular}

* The values in this panel were calculated by the author. 


\begin{tabular}{|c|c|c|c|c|}
\hline$\alpha+z \gamma \alpha$ & $I \underset{\text { "exact" }}{-F(x, t)}$ & Gamma approx. & $N P_{2}$ & $N P_{3}$ \\
\hline 2.7147 &.+265 & .4193 & .4228 & .4131 \\
\hline 4.3623 & .1364 & .1483 & . I 587 & .1425 \\
\hline 6.0100 & .04523 & $.0448 \mathrm{I}$ & .04938 & .04497 \\
\hline 7.6576 & .01401 & .01234 & .01348 & .01387 \\
\hline 9.3052 & .00352 & .00319 & .00333 & .00428 \\
\hline 12.6005 & .00022 & .00019 & .00164 & .00042 \\
\hline $\begin{array}{l}6.0741 \\
8.5387\end{array}$ & $\begin{array}{l}.4476 \\
.1502\end{array}$ & $\begin{array}{l}.4460 \\
.1535\end{array}$ & $\begin{array}{l}.4472 \\
.1587\end{array}$ & $\begin{array}{l}++444 \\
.1509\end{array}$ \\
\hline II.0032 & .03968 & .03977 & .04179 & .04000 \\
\hline I $3.467^{8}$ & .00892 & .00849 & $.0088 \mathrm{I}$ & .00920 \\
\hline I 5.9324 & .00177 & .00158 & .00157 & .00195 \\
\hline 20.8615 & .00005 & .00004 & .00003 & .00008 \\
\hline $0.2714^{8}$ & .3743 & .2639 & .3129 & $.164 I$ \\
\hline 0.79252 & .0947 & .1027 & .1587 & .0827 \\
\hline 1.31355 & .03450 & .04783 & .08152 & .04827 \\
\hline 1.83459 & .01709 & .02383 & .04195 & .03016 \\
\hline 2.35563 & .00893 & .01232 & .02156 & .01967 \\
\hline $3.3977^{\circ}$ & .00378 & $.0035 \mathrm{I}$ & .00565 & .00908 \\
\hline 0.32569 & $.380 \mathrm{r}$ & .2805 & .3226 & .1795 \\
\hline 0.89638 & .1006 & .1083 & .1587 & .0827 \\
\hline 1.46708 & .03521 & .04892 & .07856 & .0488 \\
\hline 2.03777 & .01680 & $.0235^{\circ}$ & 0.3880 & .0298 \\
\hline 2.60846 & .00855 & .01168 & .01907 & .01897 \\
\hline 3.74985 & .00365 & .00306 & .00454 & .00843 \\
\hline 2.7056 & .3992 & 4191 &.$+227^{*}$ & .4194 \\
\hline 4.3505 & .1562 &.${ }^{4} 82$ & I 587 & .1510 \\
\hline 5.9953 & .04569 & .04483 & .04947 & $.0453 \mathrm{I}$ \\
\hline 7.6402 & .01258 & .01236 & .01350 & .01201 \\
\hline $9.285 \mathrm{I}$ & $.0028 \mathrm{I}$ & .00320 & .00334 & $.0029 \mathrm{I}$ \\
\hline 12.5748 & .00012 & $.000 r 9$ & $.000 \mathrm{r} 6$ & $.0001_{4}$ \\
\hline $0.990 \mathrm{I}$ & $.367 \mathrm{I}$ & .3672 & $.3^{805}$ & .3593 \\
\hline $1.985 \mathrm{I}$ & .1353 & .1352 & .1587 & .1347 \\
\hline 3.9752 & .0184 & $.018_{4}$ & .0229 & .0194 \\
\hline 5.9653 & .0025 & .0025 & .0028 & .0029 \\
\hline 0.5854 & .3448 & .3299 & .3540 & .3040 \\
\hline 1.3505 & .1226 & .1242 & .1587 & . II 89 \\
\hline 2.8807 & .0198 & .0213 & .0297 & .0238 \\
\hline $4.4 \times 10$ & .0046 & .0040 & .0051 & .0056 \\
\hline
\end{tabular}




\section{REFERENCES}

BERGER, G. (1972) "Integration of the normal power approximation." Astin Bull. 7 , 90-95.

BOHMAN, H. and Esscher, F. (1963.64) "Studies in risk theory with numerical illustrations concerning distribution functions and stop loss premiums." Skand. Aktuar.-Tidskr. 46, 173-225; 47, 1-40.

Bühlmavi, H. (I974) Review of J. A. Beekman's Two Stochastic Processes. Astin Bull. 8, I3I-132.

KAUPPI, L. and OJANTAKANEN, P. (I969) "Approximations of the generalised Poisson function." Astin Bull. 5, 213-226.

Khamis, S. H. with RUDERT, W. (I965) Tables of the Incomplete Gamma Function Ratio. Von Liebig, Darmstadt.

Macivus, W., Oberhettinger, F. and Soni, R. P. (1966) Formulas and Theorems for the Special Functions of Mathematical Physics. SpringerVerlag, Berlin.

Pesonen, E. (I969) "NP-approximation of risk processes." Skand. Aktuar.Tidskr. 52 Suppl., 63-69. 